\title{
Clinical and Laboratory Predictors for ICU Admission among COVID-19 Infected Egyptian Patients, A multi-Center Study
}

\author{
Shimaa El Sharawy ${ }^{1}$, Ibrahim Amer ${ }^{2}$, Marwa Salama ${ }^{1}$, Walaa El-Lawaty ${ }^{3}$, \\ Mohamed Abd Elghafar ${ }^{4}$, Amany Ghazi ${ }^{5}$, Nehad Hawash ${ }^{1}$ \\ ${ }^{1}$ Department of Tropical Medicine and Infectious Diseases, Faculty of Medicine, Tanta \\ University, Egypt. \\ ${ }^{2}$ Department of Hepatology, Gastroenterology and Infectious Diseases, Faculty of \\ Medicine, Kafr El Sheikh University, Egypt. \\ ${ }^{3}$ Department of Chest Diseases, Faculty of Medicine, Tanta University, Egypt. \\ ${ }^{4}$ Department of Anesthesia, Surgical Intensive Care and Pain Management, Tanta \\ University, Egypt. \\ ${ }^{5}$ Department of Microbiology and Medical Immunology, Faculty of Medicine, Kafr El \\ Sheikh University, Egypt.
}

Corresponding Author Shimaa El Sharawy

Mobile:

01028028981

E mail:

Shaimaa.elsharawy@ med.tanta.edu.eg.

Key words: COVID-19; predictors; ICU
Background and study aim: The incremental global spread of the SARSCoV-2 virus imposes an enormous burden on medical health systems. We focused on determining the predictors for the COVID-19 patient's course of illness and what level of care will be actually needed at hospital admission.

Patients and Methods: 170 symptomatic COVID-19 Egyptian patients were gleaned from August 2020 to January 2021, were categorized into a group that managed at home or ward admitted and a group that necessitated ICU hospitalization at Tanta University or Kafr El-sheikh University isolation hospitals. Each patient's demographics, clinical, laboratory, and radiological data were gathered and several classification strategies were applied. The variables that predicted the severity of disease and ICU admission were established via logistic

\section{INTRODUCTION}

SARS-CoV-2 pandemic around the world, with fatality rates ranging from $0.4 \%$ to $7 \%$, has killed hundreds of thousands of people [1]. While the majority of COVID-19 patients have no symptoms or very modest respiratory symptoms, not demanding hospitalization, and only a minuscule proportion of patients are hospitalized owing to systemic or severe respiratory symptoms [2, 3], the virus's rapid spread is putting undue strain on public health systems [4]. So, increased medical supplies are regression. The area under the receiver operating characteristic curve was used to assess performance.

Results: The top risk variables predicting ICU admission were blood oxygen saturation $(\mathrm{P}<0.001)$, serum ferritin $(\mathrm{P}=$ $0.023)$, WHO assessment scale $(\mathrm{P}=0.001)$ and presence of fatigue $(\mathrm{P}=0.001)$ or myalgia $(\mathrm{P}=0.028)$ and with the best accuracy for WHO assessment scale $>4$ and oxygen saturation $\leq 90$ with an AUC of 0.850 (95\% CI $[0.795-0.905])$ and $0.800 \quad(95 \%$ CI $[0.735-0.865])$, respectively.

Conclusion: Fatigue, myalgia, oxygen saturation, pulse, respiratory rates, ferritin, and C-reactive protein may prove useful for physicians to distinguish which COVID-19 patients will be required to be managed critically at hospital admission.

being sought to alleviate this burden [5].

The biggest concern in the assessment of patients infected with COVID-19 in a pandemic situation is to identify patients who are already at high risk of mortality early in the disease and to give proper medical care [6]. The condition of high-risk patients, in particular, might quickly deteriorate. According to certain studies, COVID19 patients who ended up dead had minor symptoms at first but speedily escalated to a critical stage, leading to death $[7,8]$. 
Governments and hospitals have battled to allocate limited supplies, such as diagnostics, treatment in critical care units (ICUs), and ventilators, throughout this pandemic $[9,10]$. Furthermore, ICU capacity varies by country, with lesser availability in lower-middle-income parts of the world [11].

Specific evidence on the patient risk factors linked to COVID-19 mortality is scarce, and approaches to reliably predict disease severity at the time of hospital admission are inadequate [12-14]. As a result, there is a pressing need to assist field doctors in optimally triaging COVID19 patients [15].

To preserve healthcare system capacity in Egypt, the goal of this study is to investigate the prognostic usefulness of combined clinical, laboratory, and imaging results in predicting critical disease among Egyptian COVID-19 patients.

\section{PATIENTS AND METHODS}

\section{Study design and settings}

Enrollment of patients in this prospective observational study was done after Tanta University Ethical committee of scientific research approval (approval code: 33988/8/20) complying with the declaration of Helsinki. A total of 200 patients who were either home isolated or admitted to Tanta University and Kafr El-sheikh university isolation hospitals, in the period from August 2020 to January 2021, were screened for participation in this study.

\section{Inclusion criteria}

Adult ( $\geq 18$ years) patients who have diagnosed with COVID-19 infection with positive PCR test (if the first PCR test of highly suspicious critical cases was negative, it was repeated within 48 hours) and the presence of typical computed tomography (CT) features were included in this study. All patients received treatment according to the Egyptian protocol for the management of COVID-19 [16].

\section{Exclusion criteria}

Patients aged < 18 years and patients with a history of any of the following; cancer, severe kidney and liver diseases, presence of other known infection, pregnancy, taking medications before the initial visit, uncontrolled diabetes mellitus (DM) (HbA1c >9), chronic pulmonary disease, alcoholism, organ transplant, refusing to be included in this study were excluded.

\section{Method}

All of the following data were collected on admission: history taking for co-morbidities and clinical presentation, clinical examination (including vital signs assessment), laboratory investigations including; liver enzymes; alanine aminotransferase (ALT), aspartate aminotransferase (AST), AST/ALT ratio and ALT/AST ratio were calculated, renal function tests (blood creatinine), serum ferritin, Creactive protein (CRP), complete blood count; to detect total leucocytic count (TLC), neutrophil $\%$, lymphocytes $\%$, hemoglobin, platelet count, to calculate: Neutrophil-to-Lymphocyte ratio (NLR), Platelet-to-Lymphocyte ratio (PLR), pregnancy test for females in the child-bearing period. Also, the high resolution CT chest was interpreted by severity scoring. Follow-up of all included patients was done to detect the fate of every patient (either cured or died).

Patients were given scores according to severity of the disease; mild cases: patients with mild symptoms (either one or more of the following symptoms: fever, fatigue, cough, sore throat, headache, runny nose, body aches, diarrhea and or vomiting, the new loss of taste or smell) and normal imaging, moderate cases: patients with positive CT findings of COVID-19 and saturation of peripheral Oxygen $\mathrm{SpO}_{2} \geq 92 \%$, sever cases: fulfilling any of the following criteria: respiratory rate $>30$ breaths $/ \mathrm{min}, \mathrm{SpO} 2<$ $92 \%$. $\mathrm{PaO} 2 / \mathrm{FiO} 2$ ratio $<300$ or lung infiltrate $>50 \%$, critical case: patients with any of the following; respiratory failure, septic shock, and/or multi-organ dysfunction [16], and World Health Organization (WHO) assessment score: 0 $=$ no infection $1=$ no limitation of activities 2 =limitation of activities 3 =hospitalized, no oxygen therapy $4=$ oxygen by mask or nasal prong $5=$ non-invasive ventilation or high-flow oxygen $6=$ intubation and mechanical ventilation 7 =ventilation + additional organ support 8 =death [17].

\section{Statistical analysis}

IBM SPSS software package version 20.0. (Armonk, NY: IBM Corp) was administered for the analysis of the gathered data. The Kolmogorov- Smirnov was used to verify the 
normality of distribution of variables. Mean, standard deviation, median and range were used for describing quantitative variables while qualitative variables were illustrated as frequency and percentages. Chi-square test (Fisher or Monte Carl) was used for the comparison of the categorical variables between the two studied groups. Student t-test and Mann Whitney test were utilized to compare between the two groups as regard normally and not normally distributed quantitative variables respectively. Pearson coefficient was used to correlate between two normally distributed quantitative variables, while Spearman coefficient was done for abnormally quantitative variables. Univariate and multivariate regression analyses were done to detect the main independent factor for ICU admission. The area under the receiver operating characteristic (ROC) curve was calculated to measure the discriminatory power of factors predicting the need for ICU admission. $p$ value was considered significant if $<0.05$.

\section{RESULTS}

200 patients were evaluated for participation in this study. But only 170 patients were included and divided into two groups; Group I included 89 patients who were treated either at home or ward admitted; Group II included 81 patients who needed ICU admission. Group I patients has a median of age 49 years and male/female $(\mathrm{m} / \mathrm{f})$ ratio 50/39, while patients in group II has a median of age 52 years and $\mathrm{m} / \mathrm{f}$ ratio $47 / 34$ with no significant differences recorded between two studied groups as regard age, and sex $(\mathrm{P}=0.119$, 0.808 respectively) (Table 1). Various predisposing factors were recorded in patients included in both groups with no significant difference detected (Table 1).

Pulse rate, respiratory rate, and body temperature were significantly higher in ICU group $(\mathrm{P}=0.002$, $<0.001,0.028$ respectively), whereas $\mathrm{SpO}_{2}$ was significantly lower $(\mathrm{P}=<0.001)$, while blood pressure either systolic or diastolic showed no difference ( $\mathrm{P}=0.84,0.091)$ (Table 1). Several clinical manifestations were recorded in this study from them; fever, fatigue, myalgia, malaise, body aches and cyanosis were presented in higher percentage in group II $(\mathrm{P}=0.017$, $<0.001,0.033,0.021$ and $<0.001$ respectively) (Table1).
A higher percentage of group II patients had CT findings of severe infection including (ground glass/consolidation, crazy paving and vascular thickening), while ground glass/consolidation were predominant in group I $(\mathrm{P}<0.001)$ (Table 2).

Patients in group II had higher scores of both: Severity score and WHO assessment scale (P $<0.001$ ) (Table 2). As regard death rate $11(13.6 \%)$ patients in group II died; 4 females and 7 males. Hypertension, diabetes mellitus, ischemic heart disease and history of thrombosis (deep venous thrombosis, pulmonary embolism or stroke) were the main co-morbidities in those patients. 2 patients had arrhythmia (acute atrial fibrillation and premature ventricular contractions (PVC)) (Table 1).

Neutrophil \%, serum ferritin and CRP were significantly elevated in group II ( $\mathrm{P}=<0.001$, $0.012,0.001$ respectively), while platelet count was significantly decreased $(\mathrm{P}=0.045)$ (Table 2$)$. ICU admitted patients had a higher median total hospital stay days than group I (12 vs 9) $(\mathrm{P}<0.001)$ (Table 2).

A significant negative correlation was noticed between oxygen saturation level and age, pulse rate, RR, temperature, TLC, neutrophil \%, N/L ratio, serum ferritin, CRP and total hospital stay $(\mathrm{P}=0.002,0.002,<0.001,0.049,<0.001,<0.001$, $0.023,<0.001,<0.001$ and $<0.001$ respectively), while positively correlated with lymphocyte $\%$ $(\mathrm{P}=0.002)$ (Table 3). While WHO assessment scale was positively correlated with pulse rate, $\mathrm{RR}$, temperature, TLC, neutrophil \%, N/L ratio, serum ferritin, CRP and total hospital stay $(\mathrm{P}=$ $<0.001,<0.001,0.005,0.022,<0.001,0.001$, $<0.001,<0.001$ and $<0.001$ respectively), and negatively correlated with lymphocyte \% (P= 0.001) (Table 3).

Disease severity was positively correlated to age, pulse rate, RR, temperature, TLC, neutrophil \%, $\mathrm{N} / \mathrm{L}$ ratio, serum ferritin, ALT, AST, CRP and total hospital stay $(\mathrm{P}=<0.001,<0.001,<0.001$, $<0.001,<0.001,0.001,<0.001,<0.001,0.013$, $0.022,<0.001$ and $<0.001$ respectively), while negatively correlated to hemoglobin and lymphocyte $\% \quad(\mathrm{P}=\quad 0.029$ and $<0.001$ respectively) (Table 3).

A multivariate regression analysis demonstrated that, blood oxygen saturation $(\mathrm{P}<0.001)$, serum ferritin $(\mathrm{P}=0.023)$, WHO assessment scale $(\mathrm{P}=$ $0.001)$ and presence of fatigue $(\mathrm{P}=0.001)$ or 
myalgia $(\mathrm{P}=0.028)$ were independent predictors for ICU admission (Table 4).

ROC curve analysis revealed that WHO assessment scale $>4$ and oxygen saturation $\leq 90$ yielded the best accuracy for the detection of the need of ICU admission $(\mathrm{AUC}=0.850$, sensitivity $=53.09$, specificity $=98.88, \mathrm{PPV}=79.9$, $\mathrm{NPV}=69.8$ and $\mathrm{AUC}=0.800$, sensitivity $=79.1$, specificity $=64.04, \quad \mathrm{PPV}=66.7, \quad \mathrm{NPV}=77$ respectively). While pulse rate, serum ferritin, RR and CRP had lower AUC (0.641, 0.612, 0.738 and 0.650 respectively) (Table 5, Fig 1).

Table (1): Patients' basic, demographic and clinical features.

\begin{tabular}{|c|c|c|c|}
\hline & $\begin{array}{l}\text { Group I } \\
(n=89)\end{array}$ & $\begin{array}{c}\text { Group II } \\
(\mathbf{n}=\mathbf{8 1})\end{array}$ & $\mathbf{P}$ \\
\hline \multicolumn{4}{|l|}{ Age (years) } \\
\hline Median (Min. - Max.) & $49(19-84)$ & $52(22-82)$ & 0.119 \\
\hline \multicolumn{4}{|l|}{ Gender } \\
\hline Male & $50(56.2 \%)$ & $47(58 \%)$ & \multirow{2}{*}{0.808} \\
\hline Female & $39(43.8 \%)$ & $34(42 \%)$ & \\
\hline Smoker & $16(18 \%)$ & $10(12.3 \%)$ & 0.308 \\
\hline DVT/PE/stroke & $0(0 \%)$ & $3(3.7 \%)$ & ${ }^{F E} p=0.106$ \\
\hline Cardiac problems & $11(12.4 \%)$ & $13(16 \%)$ & 0.490 \\
\hline HTN & $16(18 \%)$ & $24(29.6 \%)$ & 0.074 \\
\hline DM & $23(25.8 \%)$ & $30(37 \%)$ & 0.116 \\
\hline Fever & $71(79.8 \%)$ & $75(92.6 \%)$ & $0.017^{*}$ \\
\hline Cough & $68(76.4 \%)$ & $61(75.3 \%)$ & 0.868 \\
\hline Dyspnea & $75(84.3 \%)$ & $75(92.6 \%)$ & 0.093 \\
\hline Sore throat & $18(20.2 \%)$ & $10(12.3 \%)$ & 0.167 \\
\hline Rhinorrhea & $2(2.2 \%)$ & $0(0 \%)$ & ${ }^{F E} p=0.498$ \\
\hline Fatigue & $59(66.3 \%)$ & $76(93.8 \%)$ & $<0.001^{*}$ \\
\hline Myalgia & $45(50.6 \%)$ & $54(66.7 \%)$ & $0.033^{*}$ \\
\hline Headache & $32(36 \%)$ & $38(46.9 \%)$ & 0.147 \\
\hline Anorexia & $29(32.6 \%)$ & $29(35.8 \%)$ & 0.658 \\
\hline Malaise & $32(36 \%)$ & $49(60.5 \%)$ & $0.001^{*}$ \\
\hline Aches and pain & $37(41.6 \%)$ & $48(59.3 \%)$ & $0.021^{*}$ \\
\hline Diarrhea & $28(31.5 \%)$ & $24(29.6 \%)$ & 0.796 \\
\hline Nausea & $5(5.6 \%)$ & $4(4.9 \%)$ & ${ }^{\mathrm{FE}} \mathrm{p}=1.000$ \\
\hline Anosmia & $23(25.8 \%)$ & $17(21 \%)$ & 0.456 \\
\hline Cyanosis & $21(23.6 \%)$ & $54(66.7 \%)$ & $<0.001^{*}$ \\
\hline Loss of taste & $5(5.6 \%)$ & $5(6.2 \%)$ & ${ }^{F E} p=1.000$ \\
\hline \multicolumn{4}{|l|}{ Blood pressure } \\
\hline \multicolumn{4}{|l|}{ Systolic(mmHg) } \\
\hline Mean \pm SD & $124.4 \pm 16.9$ & $123.9 \pm 16.8$ & 0.840 \\
\hline \multicolumn{4}{|l|}{ Diastolic(mmHg) } \\
\hline Mean \pm SD & $77.7 \pm 9.5$ & $80.6 \pm 13$ & 0.091 \\
\hline \multicolumn{4}{|l|}{ Pulse (beat/min) } \\
\hline Mean \pm SD & $91.2 \pm 13$ & $98.6 \pm 17.3$ & $0.002^{*}$ \\
\hline \multicolumn{4}{|l|}{ RR (breaths/min) } \\
\hline Mean \pm SD & $21 \pm 2.6$ & $24.8 \pm 4.7$ & $<0.001^{*}$ \\
\hline \multicolumn{4}{|l|}{ Temperature (Celsius) } \\
\hline Mean \pm SD & $37.9 \pm 0.7$ & $38.2 \pm 0.7$ & $0.028^{*}$ \\
\hline \multicolumn{4}{|l|}{$\mathrm{SpO}_{2}(\%)$} \\
\hline Mean \pm SD & $91.5 \pm 3.8$ & $82.6 \pm 11$ & $<0.001^{*}$ \\
\hline \multicolumn{4}{|l|}{ Fate } \\
\hline Dead & $0(0 \%)$ & $11(13,6 \%)$ & \multirow{2}{*}{$<0.001^{*}$} \\
\hline Alive & $89(100 \%)$ & $70(86.4 \%)$ & \\
\hline
\end{tabular}

DVT= deep venous thrombosis; $\mathrm{PE}=$ pulmonary embolism; $\mathrm{HTN}=$ hypertension; $\mathrm{DM}=$ diabetes mellitus; $\mathrm{RR}=$ respiratory rate; $\mathrm{SpO}_{2}=$ saturation of peripheral oxygen. 
Table (2): Laboratory and radiographic data in studied groups.

\begin{tabular}{|c|c|c|c|}
\hline & $\begin{array}{l}\text { Group I } \\
(\mathbf{n}=\mathbf{8 9})\end{array}$ & $\begin{array}{c}\text { Group II } \\
(\mathbf{n}=\mathbf{8 1})\end{array}$ & $\mathbf{P}$ \\
\hline \multicolumn{4}{|l|}{$\mathrm{HB}(\mathrm{g} / \mathrm{dl})$} \\
\hline Mean \pm SD & $12.5 \pm 1.8$ & $12.4 \pm 1.8$ & 0.764 \\
\hline \multicolumn{4}{|l|}{$\operatorname{TLC}\left(\mathbf{x 1 0}^{3} / \mu \mathrm{l}\right)$} \\
\hline Median (Min. - Max.) & $7.5(2.6-18.5)$ & $8.5(2.7-27)$ & 0.485 \\
\hline $\begin{array}{l}\text { Neutrophils \% } \\
\text { Mean } \pm \text { SD. }\end{array}$ & $71.1 \pm 10.2$ & $78.3 \pm 7.7$ & $<0.001$ \\
\hline \multicolumn{4}{|l|}{ N/L ratio } \\
\hline \multicolumn{3}{|l|}{ Lymphocytes \% } & 0.106 \\
\hline Median (Min. - Max.) & $17(5-47.0)$ & $15(4.8-36)$ & 0.196 \\
\hline \multicolumn{4}{|l|}{ Platelets $\left(\times 10^{3} / \mu \mathrm{I}\right)$} \\
\hline \multicolumn{3}{|l|}{ PL ratio } & $0.045^{*}$ \\
\hline \multicolumn{3}{|l|}{ Ferritin $(\mathbf{n g} / \mathbf{m L})$} & 0.282 \\
\hline $\begin{array}{l}\text { Median (Min. - Max.) } \\
\text { ALT(U/L) }\end{array}$ & $368(3-950)$ & $489(17.4-1672)$ & $0.012^{*}$ \\
\hline \multicolumn{3}{|l|}{$\operatorname{AST}(\mathbf{U} / \mathbf{L})$} & 0.679 \\
\hline Median (Min. - Max.) & $40(10-282)$ & $41(12-300)$ & 0.833 \\
\hline \multicolumn{4}{|l|}{ AST/ALT } \\
\hline \multicolumn{3}{|l|}{ ALT/AST } & 0.657 \\
\hline Median (Min. - Max.) & $1(0.4-3)$ & $0.9(0.3-2.9)$ & 0.784 \\
\hline \multicolumn{4}{|l|}{$\mathrm{CRP}(\mathrm{mg} / \mathrm{L})$} \\
\hline \multicolumn{4}{|l|}{ Creatinine (mg/dl) } \\
\hline Median (Min. - Max.) & $0.9(0.4-3)$ & $1(0.5-2.4)$ & 0.161 \\
\hline \multicolumn{4}{|l|}{ CT chest } \\
\hline Ground glass/consolidation & $85(95.5 \%)$ & $51(63 \%)$ & ${ }^{\mathrm{MC}} \mathrm{p}$ \\
\hline Vascular thickening & $0(0 \%)$ & $1(1.2 \%)$ & $<0.001^{*}$ \\
\hline All of those findings & $4(4.5 \%)$ & $29(35.8 \%)$ & \\
\hline \multicolumn{4}{|l|}{ Severity } \\
\hline Mild & $7(7.9 \%)$ & $0(0 \%)$ & \\
\hline Moderate & $37(41.6 \%)$ & $15(18.5 \%)$ & ${ }^{\mathrm{MC}} \mathrm{p}$ \\
\hline Severe & $45(50.6 \%)$ & $59(72.8 \%)$ & $<0.001^{*}$ \\
\hline Critical & $0(0 \%)$ & $7(8.6 \%)$ & \\
\hline Median (Min. - Max.) & $3(1-3)$ & $3(2-4)$ & $<0.001^{*}$ \\
\hline \multicolumn{4}{|l|}{ WHO assessment scale } \\
\hline Limitation of activities & $12(13.5 \%)$ & $0(0 \%)$ & \multirow{4}{*}{$<0.001^{*}$} \\
\hline Hospitalized, no oxygen therapy & $22(24.7 \%)$ & $0(0 \%)$ & \\
\hline Oxygen by mask or nasal prong & $54(60.7 \%)$ & $38(46.9 \%)$ & \\
\hline $\begin{array}{l}\text { Non-invasive ventilation or high- } \\
\text { flow oxygen }\end{array}$ & $1(1.1 \%)$ & $32(39.5 \%)$ & \\
\hline Death & $0(0 \%)$ & $11(13.6 \%)$ & \\
\hline Median (Min. - Max.) & $4(2-5)$ & $5(4-8)$ & $<0.001^{*}$ \\
\hline \multicolumn{4}{|l|}{ Total hospital stay } \\
\hline Median (Min. - Max.) & $9(0-15)$ & $12(1-53)$ & $<0.001^{*}$ \\
\hline
\end{tabular}

$\mathrm{HB}=$ Hemoglobin; $\mathrm{TLC}=$ total leucocytic count; $\mathrm{N} / \mathrm{L}=$ neutrophil/lymphocyte ratio; $\mathrm{PL}=$ platelet $/$ lymphocyte ratio; $\mathrm{AST}=$ aspartate aminotransferase; $\mathrm{ALT}=$ alanine aminotransferase; $\mathrm{CRP}=\mathrm{C}$-reactive protein; $\mathrm{CT}=$ computed tomography; $\mathrm{WHO}=$ World Health Organization; Min= minimum; Max= maximum. 
Table (3): Correlation between $\mathrm{SpO}_{2}, \mathrm{WHO}$ assessment scale, severity and different parameters in total sample $(\mathrm{n}=170)$

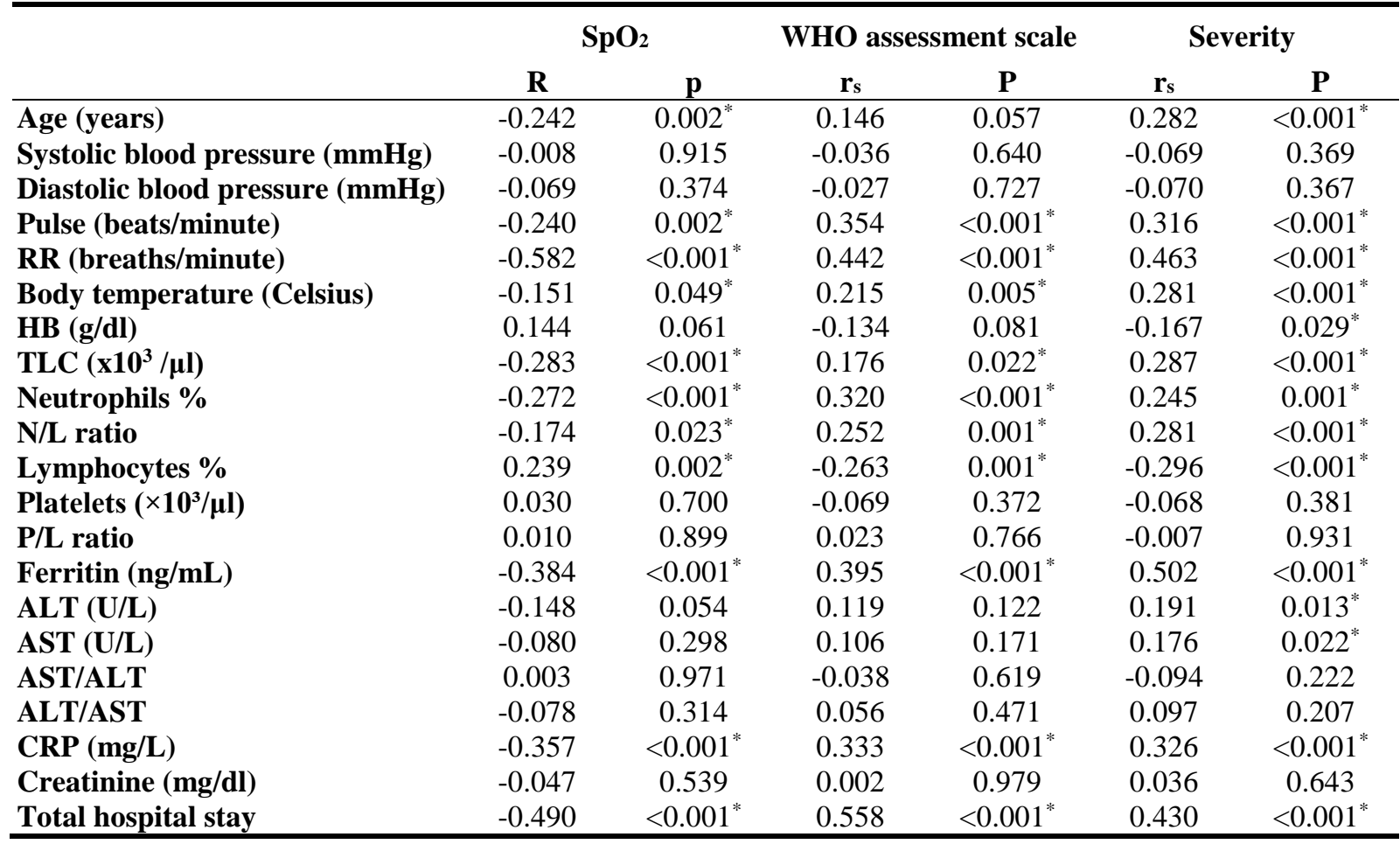

$\mathrm{RR}=$ respiratory rate; $\mathrm{HB}=$ Hemoglobin; $\mathrm{TLC}=$ total leucocytic count; $\mathrm{N} / \mathrm{L}=$ neutrophil/lymphocyte ratio; $\mathrm{PL}=$ platelet / lymphocyte ratio; AST = aspartate aminotransferase; $\mathrm{ALT}=$ alanine aminotransferase; $\mathrm{CRP}=\mathrm{C}$-reactive protein; $\mathrm{CT}=$ computed tomography.

Table (4): Univariate and multivariate Logistic regression analysis for the parameters affecting ICU $(\mathrm{n}=81)$ from ward $(\mathrm{n}=89)$.

\begin{tabular}{|c|c|c|c|c|}
\hline & \multicolumn{2}{|r|}{ Univariate } & \multicolumn{2}{|r|}{${ }^{\#}$ Multivariate } \\
\hline & $\mathbf{p}$ & OR (95\% C.I) & $\mathbf{P}$ & OR (95\% C.I) \\
\hline Pulse (beats/minute) & 0.002* & $1.033(1.012-1.055)$ & 0.059 & $0.941(0.883-1.002)$ \\
\hline RR (breaths/minute) & $<0.001 *$ & $1.304(1.183-1.438)$ & 0.896 & $1.022(0.741-1.409)$ \\
\hline Body temperature (Celsius) & $0.029^{*}$ & $1.608(1.049-2.464)$ & 0.126 & $2.117(0.811-5.530)$ \\
\hline $\mathrm{SpO}_{2}(\%)$ & $<0.001^{*}$ & $0.787(0.725-0.855)$ & $<0.001^{*}$ & $2.117(0.811-5.530)$ \\
\hline Neutrophils \% & $<0.001^{*}$ & $1.092(1.051-1.134)$ & 0.571 & $1.024(0.944-1.110)$ \\
\hline Platelets $\left(\times 10^{3} / \mu \mathrm{l}\right)$ & 0.073 & $0.997(0.993-1.0)$ & & \\
\hline Ferritin (ng/ml) & $0.004^{*}$ & $1.002(1.001-1.003)$ & $0.023^{*}$ & $0.995(0.991-0.999)$ \\
\hline $\mathrm{CRP}(\mathrm{mg} / \mathrm{L})$ & $<0.001^{*}$ & $1.014(1.007-1.022)$ & 0.441 & $1.007(0.989-1.027)$ \\
\hline Total hospital stay & $<0.001^{*}$ & $1.261(1.148-1.384)$ & 0.244 & $1.197(0.885-1.619)$ \\
\hline Fatigue & $<0.001^{*}$ & $7.729(2.826-21.135)$ & $0.001^{*}$ & $302.979(11.51-7974.88)$ \\
\hline Myalgia & $0.034^{*}$ & $1.956(1.051-3.640)$ & $0.028^{*}$ & $0.075(0.008-0.752)$ \\
\hline Aches and pain & $0.022^{*}$ & $2.044(1.109-3.769)$ & 0.404 & $2.232(0.339-14.707)$ \\
\hline Cyanosis & $<0.001^{*}$ & $6.476(3.304-12.693)$ & 0.333 & $0.333(0.036-3.089)$ \\
\hline WHO assessment scale & $<0.001 *$ & $62.086(8.520-452.415)$ & $0.001^{*}$ & $320.635(10.36-9926.64)$ \\
\hline CT $\operatorname{chest}$ (All of those findings) & $<0.001 *$ & $11.851(3.941-35.633)$ & 0.094 & $17.515(0.614-500.017)$ \\
\hline Severity & $<0.001^{*}$ & $4.319(2.307-8.083)$ & 0.284 & $0.293-0.031-2.773)$ \\
\hline
\end{tabular}

$\mathrm{RR}=$ respiratory rate; $\mathrm{SpO}_{2}=$ saturation of peripheral oxygen; $\mathrm{CRP}=\mathrm{C}$ - reactive protein; $\mathrm{WHO}=$ World Health Organization; $\mathrm{CT}=$ computed tomography. 
Table (5): Validity (AUC, sensitivity, specificity) for different parameters to discriminate ICU ( $\mathrm{n}=$ 81) from Ward $(n=89)$

\begin{tabular}{lcccccccc}
\hline & AUC & P & $\mathbf{9 5 \%}$ C.I & $\begin{array}{c}\text { Cut } \\
\text { off }\end{array}$ & Sensitivity Specificity & PPV & NPV \\
\hline Pulse & & & & & & & & \\
(beat/minute) & 0.641 & $0.002^{*}$ & $0.556-0.725$ & $>100$ & 41.98 & 83.15 & 69.4 & 61.2 \\
SpO $_{\mathbf{2}(\%)}$ & 0.800 & $<0.001^{*}$ & $0.735-0.865$ & $\leq 90$ & 79.01 & 64.04 & 66.7 & 77.0 \\
WHO assessment & 0.850 & $<0.001^{*}$ & $0.795-0.905$ & $>4$ & 53.09 & 98.88 & 97.7 & 69.8 \\
Ferritin (ng/ml) & 0.612 & $0.012^{*}$ & $0.527-0.697$ & $>368$ & 62.96 & 50.56 & 53.7 & 59.5 \\
RR (nR & 0.738 & $<0.001^{*}$ & $0.660-0.816$ & $>23$ & 62.96 & 83.15 & 77.3 & 71.2 \\
CRP(mg/L) & 0.650 & $0.001^{*}$ & $0.564-0.736$ & $>56$ & 53.09 & 82.02 & 72.9 & 65.8 \\
\hline
\end{tabular}

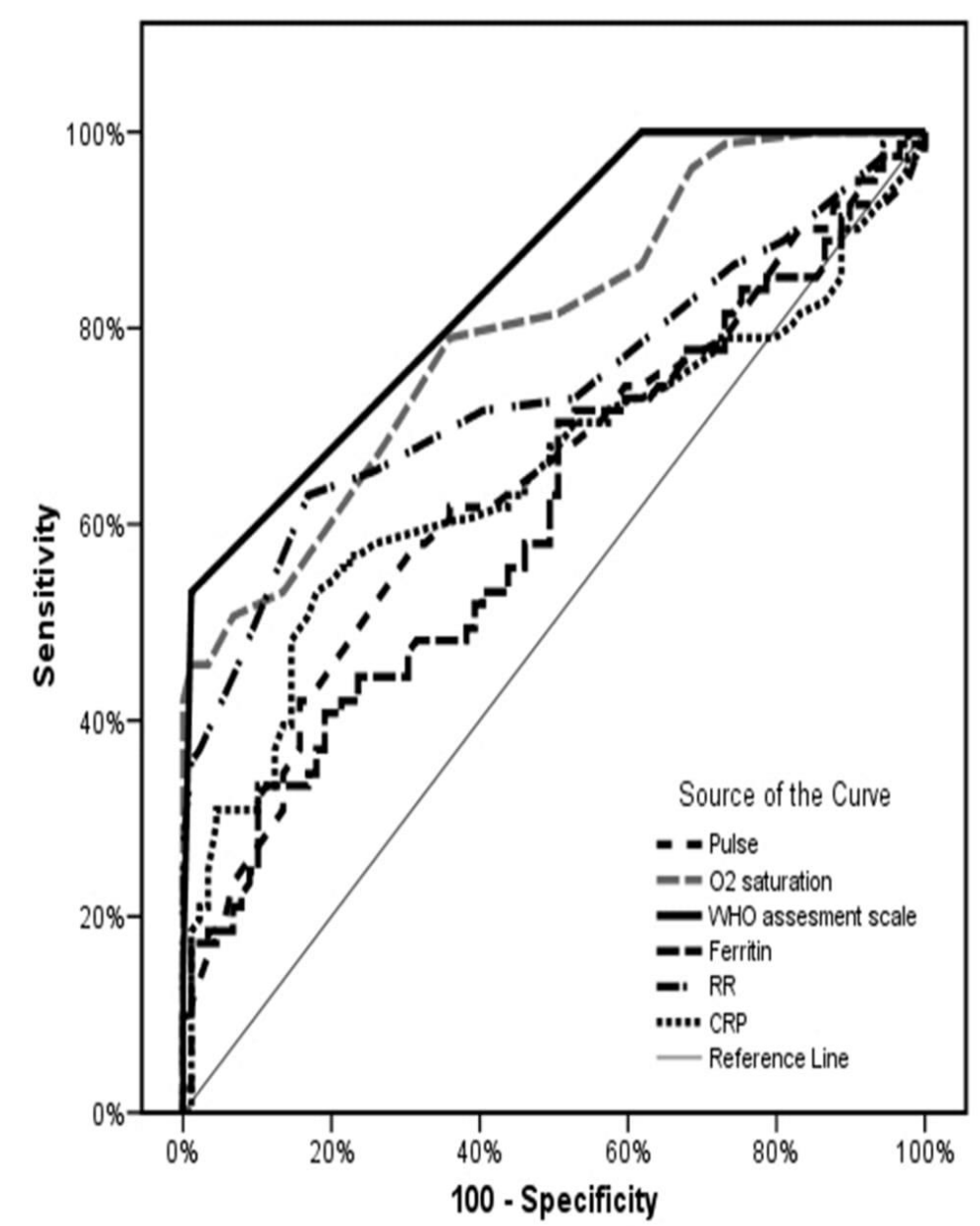

Figure (1): ROC curve for different parameters to discriminate factors determining ICU admission $(\mathrm{n}=81)$ from WARD $(\mathrm{n}=89)$

\section{DISCUSSION}

This study involved a retrospective evaluation of prospectively gathered data from 170 Egyptian patients who were either home isolated, hospitalized in a ward, or referred to an ICU. Initially, on the basis of demographic data, there were no significant variations in gender or age here between the two groups. Age did have a statistical correlation with both oxygen saturation and severity of illness; this was in the same line with prior researches encompassing age in the Covid-19 severity scores and even assumed it as one of the predictors of deaths; meanwhile, age could not be considered an independent factor for ICU admission in the present research work $[18,19]$.

Although 8 of 11 dead patients had a history of either one or more of the following conditions; 
diabetes mellitus, hypertension, deep venous thrombosis, or ischemic heart disease, there was no significant difference in preexisting medical factors between the two evaluated groups. On the contrary, predisposing illnesses such as cancer, chronic kidney disease, chronic lung disease, diabetes mellitus, hypertension, and others, have been identified as risk factors for severity, intubation risk, and death in earlier researches [3, 14]. This disparity could be attributable to the current study exclusion criteria, which included both cancer patients and chronic chest patients.

Since the emergence of the pandemic, a wide range of symptoms and signs have been recorded, all of which are non-specific for COVID-19, though fever, fatigue, malaise, myalgia, body aches, and cyanosis were seen in a higher percentage of ICU patients than in-home isolated or ward admitted patients. Furthermore, fatigue and myalgia were found to be independent predictors for ICU admission need. In accordance with our result, $\mathrm{Li}$ et al 2020 concluded that muscle and joint pain are predictors of the severity of COVID-19 [20].

Unlike previous studies that linked bradycardia to community-acquired pneumonia [21] or the severity of COVID-19 [22], ICU patients had significantly higher respiratory rates, body temperatures, and pulse rates. Furthermore, only two ICU admitted patients had bradycardia, while the majority had either normal or increased pulse rates. This increase in pulse rate can be attributed to many influences, including increased body temperature ( as pulse increases 9.46 beats $/ \mathrm{min} /{ }^{\circ} \mathrm{C}$ in female patients and 7.24 beats $/ \mathrm{min} /{ }^{\circ} \mathrm{C}$ in male patients for every $1{ }^{\circ} \mathrm{C}$ increase in body temperature) [23], cardiac affection caused by COVID-19 infection [24], and associated inflammation. Moreover, in this study, 4 out of 11 dead patients had arrhythmia and ischemic heart attack. So pulse rate can be used as a rapid, simple, and bedside indicator of disease severity. Therefore, this finding highlights the importance of conducting ECG as a routine for COVID-19 infected patients.

Oxygen saturation, in previous studies, was proved to be associated with severity and mortality [25] and is incorporated in various COVID-19 management protocols. This is the same as in this study, where it was one of the independent predictors of ICU admission, with moderate sensitivity and specificity, at a cutoff value $\leq 90$.
The level of serum ferritin had been posited as one of the predictors of poor outcome in COVID-19 sufferers. Higher levels of serum ferritin were associated with higher odds of ICU admission through both univariate and multivariate analyses in this work, which was comparable to earlier studies that found an association between raised ferritin count and fatality, but with a lower cut off value (300 $\mathrm{ng} / \mathrm{ml})$ vs $(368 \mathrm{ng} / \mathrm{ml})$ in our study $[\mathbf{1 , 1 4 ]}$.

The link between the severity of infection and lymphopenia had been hypothesized, although it is not disease-specific as it can take place with any viral infection [26]. Though some of our patients had lymphopenia, lymphocyte percentage and N/L ratio did not show any significant difference between the two studied groups while they were strongly correlated with the severity of the disease and oxygen saturation, this result is corroborated by previous studies [27, 28]. Consistent with previous research [29], the percentage of neutrophils throughout ICU patients seemed to be comparatively high and was positively correlated with the severity of illness, and it was one of the crucial variables in univariate regression analysis. It can still be clarified by the virus's capabilities to wreck epithelial walls, distorting airway surfactant, and consequently results in secondary bacterial infection [30].

Among ICU patients, the platelet count had declined sharply, which was in line with prior research that attributed thrombocytopenia to both the seriousness of covid-19 \& myocardial affection [31]. On the other hand, a study by $\mathbf{Q u}$ et al revealed that patients with a higher platelet count and $\mathrm{P} / \mathrm{L}$ ratio had an even worse fate. This divergence could be related to the small sample size of 30 patients in their study [32]. But, after performing univariate and multivariate analyses, platelet count cannot be regarded as an independent predictor of severity.

ALT and AST were analyzed for the recognition of liver cellular injury; they were found to be raised within many patients in both groups, and they had a positive correlation with the degree of illness severity, but no significant difference was recorded between the both tested groups. As a result, ALT and AST could not be included among the factors determining ICU admittance, in conversely to a previous study [33], which recommended ALT and AST as factors determining both ICU transferring hence the 
need for mechanical ventilation. This difference could be due to sample size dissimilarities.

CRP is a non - specific indicator of inflammation which arises in infection or inflammation [34], has already been postulated as a key predictor of COVID-19 infection as well as intensity, and even some publications have consistently demonstrated its rising before other hematological indicators [35]. Even though CRP, in our study, was considerably higher in the ICU group and revealed an evident correlation with both oxygen saturation and severities, it could not be considered an independent forecaster of ICU admission since it was one of the crucial variables in univariate but not multivariate analysis, in contrast to previous studies [36, 37].

Numerous studies have illustrated the practical value of CT chest not just as a detector of disease severity but also as a diagnostic instrument in areas with limited resources [38], and this is the same in this study as a higher proportion of cases who mandated ICU admission had worse CT signs of infection.

On the one hand, our study had some strength; first, it was a multicenter study; second, it was a prospective study. On the other hand, there were some limitations, such as missing data that forced us to erase D dimer \& other tests indicating coagulation profile, as well as the small sample size, necessitating further research with a larger cohort to validate our results.

In conclusion, in Egypt, fatigue, myalgia, oxygen saturation, pulse, and respiratory rates, ferritin and CRP; within these limited resources; are simple, rapidly monitored predictors of severity and the demand for ICU admission among COVID-19 sufferers.

\section{Abbreviations:}

SARS-CoV-2: severe acute respiratory syndrome coronavirus 2

ALT: alanine aminotransferase

AST: aspartate aminotransferase

COVID-19: coronavirus disease 2019

CRP: C- reactive protein

CT: computed tomography

DM: diabetes mellitus

ICU: intensive care unit

NLR: Neutrophil-to-lymphocyte ratio

PCR: polymerase chain reaction

ROC: receiver operating characteristic

SpO2: Saturation of peripheral oxygen

TLC: total leucocytic count
PLR: Platelet-to-lymphocyte ratio

AUC: area under curve

PVC: premature ventricular contractions

WHO; world health organization; RR= respiratory rate

HB: hemoglobin

HTN: hypertension

PE: pulmonary embolism

DVT: deep venous thrombosis

PPV; positive predictive value

$\mathrm{NPV}=$ negative predictive value

\section{Acknowledgment}

The authors thank all colleagues at Tanta University and Kafr El-Sheikh university isolation hospitals who helped to conduct this work.

Author contribution: We declare that all listed authors have made substantial contributions to all of the following three parts of the manuscript:

- Research design, or acquisition, analysis or interpretation of data

- Drafting the paper or revising it critically

- Approving the submitted version

\section{Funding}

None

\section{Conflict of interest}

The authors declare that they have no competing interests.

\section{Ethical consideration}

All included patients approved for participation before enrollment, data included in this research was accessed by the contributing authors, reviewed and agreed on the final manuscript. Tanta University Ethical committee of scientific research approved the study.

\section{Highlights}

SARS-CoV-2 pandemic around the world increased the need for medical supplies to alleviate this burden.

Many countries as Egypt have limited supplies especially critical care units (ICUs) and ventilators.

The aim of our work is to investigate the prognostic value of combined clinical, laboratory, and imaging results on admission in predicting critical COVID-19 cases that will need extra care and ICUs. 


\section{REFERENCES}

1. Wu C, Chen X, Cai Y, Xia J, Zhou X, Xu S, et al. Risk factors associated with acute respiratory distress syndrome and death in patients with coronavirus disease 2019 pneumonia in Wuhan, China. JAMA Intern Med. 2020; 180(7):934.

2. Huang C, Wang Y, Li X, Ren L, Zhao J, Hu Y, et al. Clinical features of patients infected with 2019 novel coronavirus in Wuhan, China. Lancet 2020; 395(10223):497-506

3. Guan WJ, Ni ZY, Hu Y, Eastin C, Eastin T. Clinical characteristics of coronavirus disease 2019 in China. $N$ Engl J Med 2020; 382(18):1708-1720.

4. Wang C, Horby PW, Hayden FG, Gao GF. A novel coronavirus outbreak of global health concern. Lancet. 2020;395:470-3.

5. Ranney ML, Griffeth V, Jha AK. Critical supply shortages - the need for ventilators and personal protective equipment during the Covid-19 pandemic. New England J Med. 2020;382:e41.

6. Li C, Ye J, Chen Q, Hu W, Wang L, Fan Y, et al. Elevated lactate dehydrogenase (LDH) level as an independent risk factor for the severity and mortality of COVID-19. Aging (Albany NY) 2020 Aug 14;12(15):15670-15681

7. Luo L, Xu M, Du M, Kou H, Liao D, Cheng Z, et al. Early coagulation tests predict risk stratification and prognosis of COVID-19. Aging (Albany NY) 2020; 12(16):15918-15937

8. Lai C, Liu YH, Wang C, Wang Y, Hsueh S, Yen $\mathrm{M}$, et al. Asymptomatic carrier state, acute respiratory disease, and pneumonia due to severe acute respiratory syndrome coronavirus 2 (SARSCoV-2): Facts and myths. J MicrobiolImmunol Infect. 2020 Jun; 53(3):404-412

9. At the Top of the Covid-19 Curve, How Do Hospitals Decide Who Gets Treatment? - The New York Times, (n.d.). https://www.nytimes.com/2020/03/31/us/coronavi rus-covid-triage-rationing-ventilators.html (accessed April 29, 2020).

10. The Hardest Questions Doctors May Face: Who Will Be Saved? Who Won't? - The New York Times, (n.d.). https://www.nytimes.com/2020/03/ 21/us/coronavirus-medical-rationing.html (accessed April 29, 2020).

11. Phua J, Weng L, Ling L, Egi M, Lim CM, Divatia $\mathrm{JV}$, et al. Intensive care management of coronavirus disease 2019 (COVID-19): challenges and recommendations. Lancet Respiratory Med. 2020;8:506-17

12. Richardson S, Hirsch JS, Narasimhan $M$, Crawford JM, McGinn T, Davidson KW, et al.
Presenting characteristics, comorbidities, and outcomes among 5700 patients hospitalized with COVID-19 in the New York City Area. JAMA. 2020;323(20):2052-2059.

13. Tian W, Jiang W, Yao J, Nicholson CJ, Li RH, Sigurslid $\mathrm{HH}$, et al. Predictors of mortality in hospitalized COVID-19 patients: a systematic review and meta-analysis. $J$ Med Virol. 2020:92(10):1875-1883.

14. Zhou F, Yu T, Du R, Fan G, Liu Y, Liu Z, et al. Clinical course and risk factors for mortality of adult inpatients with COVID-19 in Wuhan, China: a retrospective cohort study. Lancet 2020; 395(10229):1054-62.

15. Wang D, Hu B, Hu C, Zhu F, Liu X, Zhang J, et al. Clinical Characteristics of 138 Hospitalized Patients With 2019 Novel Coronavirus-Infected Pneumonia in Wuhan, China. JAMA. 2020; 323(11):1061-9.

16. Ministry of health and population, Egypt. Management protocol for COVID-19 patients. Version 1.4/ November 2020.

17. World health organization. WHO R and D blue print novel Coronavirus COVID-19 therapeutic trial synopsis. February 2020.

18. Cecconi M, Piovani D, Brunetta E, Aghemo A, Greco M, Ciccarelli M, et al. Early predictors of clinical deterioration in a cohort of 239 patients hospitalized for Covid-19 infection in Lombardy, Italy. J Clin Med Res. 2020;9(5):1548.

19. Imam Z, Odish F, Gill I, O'Connor D, Armstrong J, Vanood A, et al. Older age and comorbidity are independent mortality predictors in a large cohort of 1305 COVID-19 patients in Michigan, United States. J Intern Med 2020; 288(4): 469-476.

20. Li L, Sun W, Han M, YingY and Wang Q. A Study on the Predictors of Disease Severity of COVID-19. Med Sci Monit, 2020; 26: e927167.

21. Aliberti S, Tobaldini E, Giuliani F, Nunziata V, Casazza G, Suigo G, et al. Cardiovascular autonomic alterations in hospitalized patients with community acquired pneumonia. Respir Res. 2016; 17(1):98.

22. Nemechek P. Pulse rate variability as a biomarker of COVID-19 infection,hospital risk stratification, and post hospitalization recovery. Immunol Infect 2020; 1(1).

23. Broman ME, Vincent JL,Ronco C, Hansson F, Bell M. The Relationship Between Heart Rate and Body Temperature in Critically Ill patients. Critical Care Medicine 2021; 49( 3): e327-e331.

24. Yu CM, Wong RS, Wu EB, Kong S-L, Wong J, Yip GW-K, et al. Cardiovascular complications of 
severe acute respiratory syndrome. Postgrad Med J. 2006;82(964):140-144.

25. Xie J, Covassin N, Fan Z, Singh P, Gao W, Li G, et al. Association Between Hypoxemia and Mortality in Patients With COVID-19. Mayo Clin Proc. 2020;95(6):1138-1147

26. Bellelli V, d'Ettorre G, Celani L, Borrazzo C, Ceccarelli G, Venditti M. Clinical significance of lymphocytopenia in patients hospitalized with pneumonia caused by influenza virus. Crit Care 2019; 23: 330 .

27. Tan L, Wang Q, Zhang D, Ding J, Miao H. Lymphopenia predicts disease severity of COVID19: a descriptive and predictive study. Signal Transduct Target Ther. 2020;5(1):33..

28. Ma A, Cheng J, Yang J, Dong M, Liao X, Kang Y. Neutrophil-to-lymphocyte ratio as a predictive biomarker for moderate-severe ARDS in severe COVID-19 patients. Crit Care. 2020;24(1):288.

29. Chen R, Sang L, Jiang M, Yang Z, Jia N, Fu W, et al. Longitudinal hematologic and immunologic variations associated with the progression of COVID-19 patients in China. J Allergy Clin Immunol. 2020;146(1):89-100.

30. Zhou C, Huang Z, Tan W, Li X, Yin W, et al.. Predictive factors of severe coronavirus disease 2019 in previously healthy young adults: a singlecenter, retrospective study. Respiratory Research 2020; $21: 157$

31. Lippi G, Plebani M, Henry BM. Thrombocytopenia is associated with severecoronavirus disease 2019 (COVID-19) infections: A meta-analysis. Clin Chim Acta 2020; $13 ; 506: 145-148$.
32. Qu R, Ling Y, Zhang YH, Wei LY, Chen X, Li $\mathrm{XM}$, et al. Platelet-to-lymphocyte ratio is associated with prognosis in patients with coronavirus disease-19. J Med Virol 2020; 92(9):1533-1541.

33. Piano S, Dalbeni A, Vettore E, Benfaremo D, Mattioli M, Gambino CG, et al. Abnormal liver function tests predict transfer to intensive care unit and death in COVID-19. Liver Int 2020; 40(10):2394-2406.

34. Thompson D, Pepys MB, Wood SP. The physiological structure of human C-reactive protein and its complex with phosphocholine. Structure 1999 7(2):169-177.

35. Ji W, Bishnu G,Cai Z, Shen X. Analysis clinical features of COVID-19 infection in secondary epidemic area and report potential biomarkers in evaluation. MedRxiv 2020.

36. Wang G, Wu C, Zhang Q, Wu F, Yu B, Lv J, et al. C-Reactive Protein Level May Predict the Risk of COVID-19 Aggravation. Open Forum Infect Dis 2020; 7 (5):ofaa153.

37. Luo X, Zhou W, Yan X, Guo T, Wang B, Xia H, et al. Prognostic value of C-reactive protein in patients with corona virus19. Clin Infect Dis 2020; 71(16): 2174-2179.

38. Marin BG, Aghagoli G, Lavine K, Yang L, Siff EJ, Chiang SS, et al. Predictors of COVID-19 severity: A literature review. Rev Med Virol. 2021; 31(1): 1-10. 